\title{
MAGMATISMO RAPAKIVI EN LA CUENCA MEDIA DEL RÍO INÍRIDA, DEPARTAMENTO DE GUAINÍA, COLOMBIA
}

\author{
Amed Bonilla ${ }^{1}$; José Carlos Frantz ${ }^{2}$; Juliana Charão-Marques²; \\ Thomas Cramer ${ }^{1,3}$; José Alejandro Franco ${ }^{1}$; Zeze Amaya ${ }^{1}$
}

DOI: http://dx.doi.org/10.18273/revbol.v38n1-2016001 (c) (1) Ð

Forma de citar: Bonilla, A., Frantz, J.C., Charão-Marques, J., Cramer, T., Franco, J.A., Amaya, Z. 2016. Magmatismo rapakivi en la cuenca media del río Inírida, departamento de Guainía, Colombia. Boletín de Geología, 38 (1): 17-32.

\section{RESUMEN}

Durante el Mesoproterozoico varios granitos rapakivi intruyeron el basamento cristalino en el oriente colombiano aflorando en varios sitios como en las comunidades indígenas de Danta y Matraca, en la cuenca media del río Inírida en el departamento de Guainía, donde están cubiertos con rocas sedimentarias del Terciario y depósitos cuaternarios. Análisis petrográficos y geoquímicos revelan que se trata de un cuerpo porfirítico, holocristalino, leucocrático, grosogranular y de composición monzonítica a granodiorítica con textura rapakivi tipo piterlita, indicando afinidad anorogénica. Hemos designado informalmente este cuerpo plutónico como granito rapakivi de Matraca e inicialmente fue asociado con el gran Evento Parguenze descrito en Venezuela (método convencional $\mathrm{U} / \mathrm{Pb}$ en circones, $1.550 \mathrm{Ma}$ ). Sin embargo, las recientes dataciones $\mathrm{U} / \mathrm{Pb}$ en circones con LA-ICP-MS establecen una edad concordante de $1.343 \pm 8$ Ma para su cristalización que marca un magmatismo de 100-200 Ma más joven, pero que a su vez representa mayor concordancia con las recientes edades mediante el mismo método para el Granito de Parguaza en Colombia de 1.390-1.400 Ma, lo cual nos permite suponer intrusiones episódicas de granitos tipo "A" emplazados entre 1.300-1.400 Ma y parcialmente enriquecidos en mineralizaciones de $\mathrm{Nb}$, Ta, REE y $\mathrm{Sn}$.

Palabras clave: granito rapakivi, Complejo Mitú, Colombia, Guainía.

\section{RAPAKIVI MAGMATISM IN THE MIDDLE INIRIDA BASIN, GUAINÍA DEPARMENT, COLOMBIA.}

\begin{abstract}
In eastern Colombia, the crystalline basement is intruded by several anorogenic granites of Mesoproterozoic age. One of these anorogenic granitic intrusions outcrops in the area of the indigenous Matraca and Danta communities, at the middle Inirida River Basin, and is mostly covered by Tertiary sedimentary rocks and Quaternary deposits. Petrographic and geochemical analyses reveal them as holocrystalline, leucocratic, and coarse-grained monzonite to granodiorite with Pyterlite-type rapakivi texture indicating anorogenic affinity. We named this plutonic body informally as Matraca rapakivi granite, which was initially correlated with the Parguazan Event (conventional method in zircons, $1550 \mathrm{Ma}$ ) described in Venezuela. However, LA-ICP-MS $\mathrm{U} / \mathrm{Pb}$ zircon dating yields a concordant zircon enclosure age of $1343 \pm 8 \mathrm{Ma}$ for the magma crystallization, in other words a 100-200 Ma younger magmatism, but also shows a coincidence with our ages of the Parguaza Granite in Colombia (LA-ICP-MS U/Pb zircon, 1390-1400 Ma). These ages suggest episodic intrusions of A-type granites between 1300-1400 Ma, associated with Nb, Ta, REE and Sn mineralizations.
\end{abstract}

Keywords: Rapakivi granite, Mitu Complex, Colombia, Guainía

${ }^{1}$ Grupo de Estudios en Geología Económica y Mineralogía Aplicada (GEGEMA), Universidad Nacional de Colombia. Bogotá, Colombia, abonillape@unal.edu.co,jafrancov@unal.edu.co,zamayap@unal.edu.co.

${ }^{2}$ Laboratório de Geologia Isotópica, Instituto de Geociencias, Universidade Federal do Rio Grande do Sul. Porto Alegre, R.S, Brasil,jose.frantz@ufrgs.br, juliana.marques@ufrgs.br.

${ }_{3}^{3}$ Departamento de Geociencias, Universidad Nacional de Colombia, Ciudad Universitaria. Bogotá, Colombia, thcramer@ unal.edu.co 


\section{INTRODUCCION}

Los granitos rapakivi son granitos tipo A, en su mayoría asociados a un magmatismo bimodal que presentan una textura rapakivi, i.e. feldespatos alcalinos grandes, muchas veces ovoides, normalmente rodeados por una aureola de oligoclasa-andesina (Vorma, 1976). Granitos con textura rapakivi bien desarrollada son llamados wiborgitas, mientras que si los feldespatos alcalinos carecen de una aureola de plagioclasa pronunciada son llamados piterlitas. Según Vorma (1976) el feldespato alcalino y el cuarzo cristalizan en dos generaciones siendo la generación más temprana cuarzo de alta temperatura en forma de gotas (drop-like quartz), como característica para la identificación de granitos rapakivi.

Generalmente los granitos rapakivi están asociados a zonas de adelgazamiento cortical, siendo comunes en cratones precámbricos de todos los continentes con un intervalo muy marcado de emplazamiento de 1,75-1,0 Ga entre corteza Paleo-Mesoproterozoica (2-1,5 Ga). Esta corteza presenta generalmente metamorfismo regional iniciado 100-350 Ma antes de la intrusión, lo que sugiere una conexión entre los eventos orogénicos y el magmatismo rapakivi (Rämö and Haapala, 2005). Algunos autores los enmarcan en un ambiente postorogénico (Vorma, 1976; Maniar and Piccoli, 1989) y otros como anorogénico (Anderson and Bender, 1989). A varios de estos granitos rapakivi anorogénicos están asociadas pegmatitas con potencial valor económico. Entre estas pegmatitas - principalmente miarolíticas - la más antigua (ca. 1,73 Ga) pertenece al Escudo Ucraniano (Tkachev, 2011). Otras ocurrencias famosas son asociadas a granitos rapakivi del Escudo Fennoscandiano (1,67 - 1,47 Ga), especialmente el Batolito de Wiborgo (Rämö and Haapala, 1995).

Varios granitos rapakivi forman parte del Cratón Amazónico ubicado al NE del continente suramericano. El Cratón Amazónico se formó durante el Paleo y Mesoproterozóico por la adición de material cortical proveniente del manto superior (Tassinari and Macambira, 1999); inicialmente Amaral (1974) distinguió tres provincias cratónicas (oriental, central y occidental) y posteriormente se propuso una división en dos provincias estructurales separadas por la cuenca del Río Amazonas (Almeida et al., 1981), al sur la Provincia Tapajós (Escudo Brasilero Central o Cratón de Guaporé) y al norte la Provincia Rio Branco (Escudo de Guyana).

Diferentes modelos combinando edades radiométricas, datos geofísicos (gravimétricos y magnetométricos) y posteriormente estudios geocronológicos de baja y alta resolución han sido propuestos para explicar la evolución tectono-geológica del Cratón Amazónico, donde se enmarca el papel de los granitos anorogénicos. Se pueden remarcar tres tipos de investigaciones e hipótesis:

a) Costa e Hasui (1997) sugieren, basados en datos geofísicos de magnetometría y gravimetría, que el cratón se haya conformado por 12 bloques antiguos constituidos por complejos gnéisicos con metamorfismo de grado medio y secuencias tipo greenstone que se amalgamaron por procesos colisionales diacrónicos durante el Arcaico y el Proterozoico; sus márgenes son cinturones altamente deformados (terrenos granulíticos) y reactivados en períodos posteriores. Aquí el magmatismo anorogénico es admitido como un aspecto importante durante esta reactivación (Amaral, 1974; Almeida et al., 1981; Santos e Loguercio, 1984; Hasui and Almeida, 1985).

b) Basados en datos geocronológicos obtenidos por métodos de baja resolución (predominantemente $\mathrm{K}-\mathrm{Ar}$ y $\mathrm{Rb}-\mathrm{Sr}$ ) y algunas veces $\mathrm{Sm}-\mathrm{Nd}$ para dataciones en terrenos deformados varios autores (Cordani et al., 1979; Cordani and Brito-Neves, 1982; Teixeira et al., 1989; Tassinari et al., 1996; Sato e Tassinari, 1997) proponen la preexistencia de un núcleo antiguo con terrenos rodeados por cinturones móviles, en donde el magmatismo anorogénico intruyó provincias más antiguas formadas por un magmatismo intra-cratónico posterior a una actividad orogénica preexistente en una margen de placa.

c) Utilizando datos geocronológicos de alta resolución ( $\mathrm{U}-\mathrm{Pb}$ en circones, método convencional y SHRIMP), y algunas dataciones Sm-Nd y RbSr, Santos et al. (2000) sugieren ocho provincias geotectónicas generadas por acreción relacionada a la formación de arcos magmáticos y/o reciclaje de corteza continental.

Los modelos anteriormente descritos no son libres de algunas limitaciones en las divisiones propuestas. Los estudios de campo realizados posteriormente (Santos et al., 2000) no comprobaron la presencia de terrenos de alto grado de metamorfismo (granulitas) postulados en la propuesta a). La escasez de datos de campo y los datos geocronológicos recomiendan una revisión con métodos más adecuados para la propuesta b) mientras para la hipótesis c) se debe considerar que no todas las provincias sugeridas presentan un nivel de conocimiento satisfactorio que permita determinar con precisión sus límites. Por ejemplo, la provincia 
K'Mudku, representada por una zona de cizalla (shearzone) que afectó litologías de diversas provincias, permanece geológicamente poco conocida. Por otro lado, los límites entre las provincias Rio Negro y Rondônia - Juruena, así como entre Rio Negro y Tapajós-Parima son desconocidos y carecen de investigaciones complementarias (Santos et al., 2000).
Tanto Tassinari and Macambira (1999) como Santos et al., (2000) concuerdan en que los principales eventos de adición de material del manto a la corteza ocurrieron durante determinadas etapas que dividen al Cratón Amazónico en distintas provincias geocronológicas (TABLA 1).

TABLA 1. Provincias geocronológicas del Cratón Amazónico según Tassinari and Macambira (1999) y Santos et al. (2000).

\begin{tabular}{cccc}
\hline \multicolumn{2}{c}{ Tassinari y Macambira (1999) } & Santos et al., (2000) \\
\hline Provincias & Edad & Provincias & Edad \\
\hline Amazónica Central (CAP) & $>2,3 \mathrm{Ga}$ & Carajas-Imataca & $3,10-2,53 \mathrm{Ga}$ \\
Maraoni-Itacaiunas (MIP) & $2,2-1,95 \mathrm{Ga}$ & Transamazónica & $2,25-2,00 \mathrm{Ga}$ \\
Ventuari-Tapajós (VTP) & $1,95-1,80 \mathrm{Ga}$ & Tapajos-Parima & $2,10-1,87 \mathrm{Ga}$ \\
Río Negro-Juruena (RNJP) & $1,80-1,55 \mathrm{Ga}$ & Central Amazónica & $1,88-1,70 \mathrm{Ga}$ \\
Rondonia-San Ignacio (RSIP) & $1,60-1,30 \mathrm{Ga}$ & Río Negro & $1,86-1,52 \mathrm{Ga}$ \\
Provincia Sunsás (SP) & $1,3-1,0 \mathrm{Ga}$ & Rondónia-Juruena & $1,76-1,47 \mathrm{Ga}$ \\
- & - & Sunsas & $1,33-0,99 \mathrm{Ga}$ \\
\hline
\end{tabular}

El Granito de Parguaza es considerado como uno de los granitos anorogénicos más grandes del mundo, puesto que aflora a lo largo del margen continental del río Orinoco y se extiende desde el territorio venezolano hasta el extremo oriental de Colombia formando así parte de las rocas del Escudo Guyanés. Se le ha asignado la edad obtenida en Venezuela de 1.531$1.545 \mathrm{Ma}$ mediante el método $\mathrm{Rb} / \mathrm{Sr}$ en roca total y $\mathrm{U} /$ $\mathrm{Pb}$ por disolución de circones (Gaudette et al., 1978), pero recientemente (Bonilla et al., 2013) obtuvieron dos edades concordantes de 1.401 y 1.392 Ma mediante el método LA-ICP-MS U/Pb en circones en Colombia, lo cual, o surgiere una historia de emplazamiento y cristalización larga desde el núcleo al borde de casi 150 $\mathrm{Ma}$, o indica que los procesos magmáticos anorogénicos eran más complejos y de diferentes episodios por lo menos en esta parte del cratón (Bonilla et al., 2013). Normalmente un cuerpo intrusivo se enfría y cristaliza desde los bordes hacia el núcleo, por lo cual la edad en el lado colombiano debería ser mayor que en el centro venezolano.

Otros cuerpos de textura rapakivi con fenocristales de feldespato potásico rosado rodeados por una aureola de plagioclasa han sido reportados en las memorias de la Plancha 297 localizados principalmente en los afluentes de caño Chaquita y la desembocadura de los ríos Guaviare y Atabapo en el departamento de Guainía, los cuales son intrusivos dentro del Complejo Mitú
(FIGURA 1) (López et al., 2010; INGEOMINAS, 2010). El Complejo Mitú (López et al., 2007) corresponde al basamento cristalino que constituye la parte más oriental del territorio colombiano dentro del Escudo Guyanés repartido en los departamentos de Guainía, Vaupés y Caquetá, con localidades tipo en los ríos Vaupés, Guainía, Atabapo y Negro y suprayacido por unidades meta-sedimentarias y vulcano-sedimentarias del Proterozoico, Paleozoico y del Cenozoico.

Este trabajo presenta datos petrográficos, geoquímicos y mineralógicos obtenidos a través del proyecto de investigación "Caracterización de depósitos aluviales con manifestaciones de tantalio y niobio ("coltán”) en las comunidades indígenas de Matraca y Caranacoa, departamento de Guainía-" realizado entre 2010 y 2011 mediante convenio entre la Universidad Nacional de Colombia-Sede Bogotá e INGEOMINAS (hoy Servicio Geológico Colombiano), en el cual se reportan y describen por primera vez granitos rapakivi en la cuenca media del río Inírida, con ocurrencias minerales de $\mathrm{Nb}$, $\mathrm{REE}, \mathrm{U}$ y $\mathrm{Th}$ en roca in-situ y en depósitos aluviales (Bonilla et al., 2010; Cramer et al., 2010a,b; Cramer et al., 2011). Adicionalmente, se integran los primeros datos geocronológicos utilizando métodos isotópicos de alta resolución y precisión para este cuerpo en el marco del proyecto "Investigación de minerales estratégicos, industriales y materiales de construcción, región Llanos". 


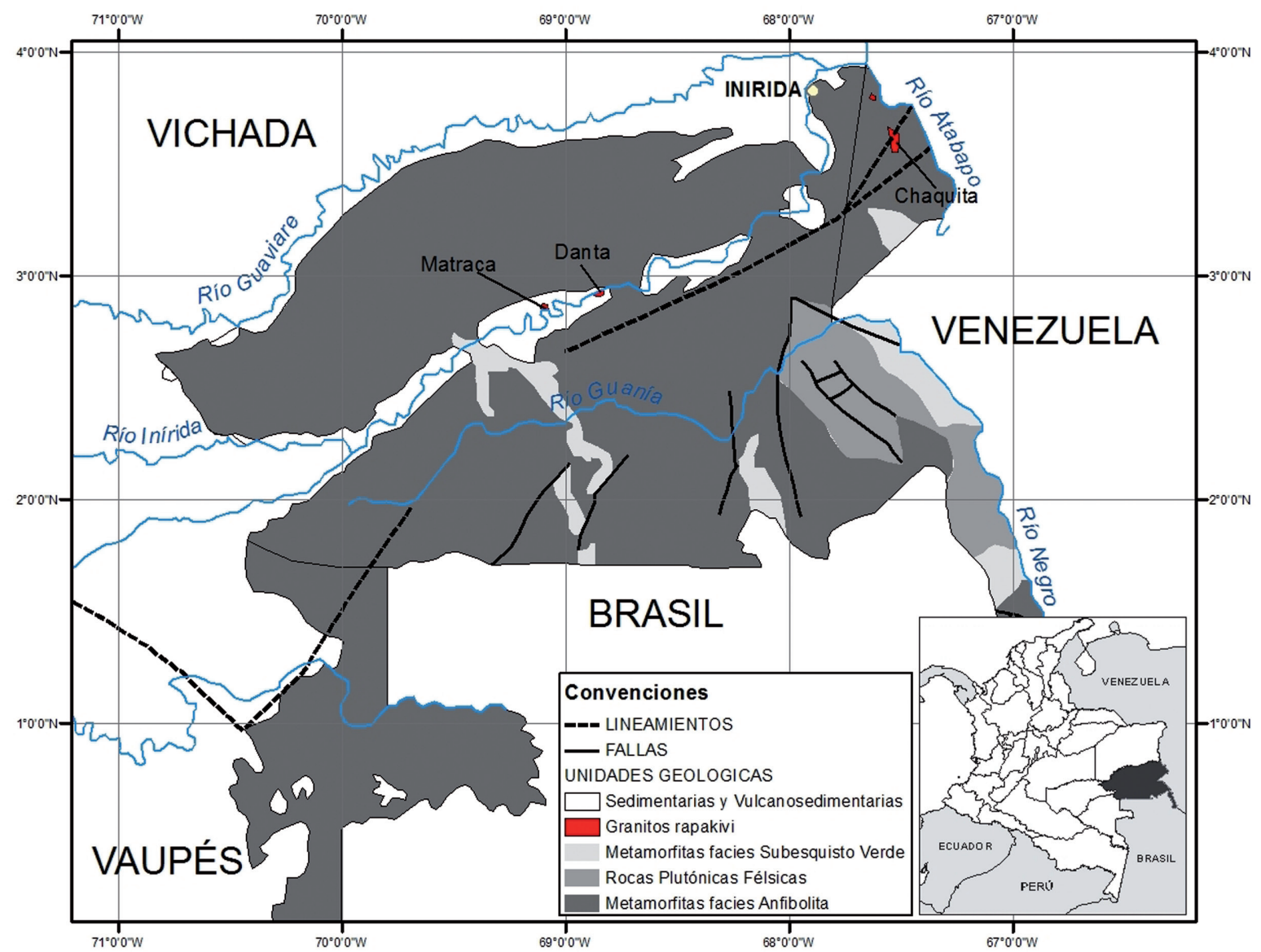

FIGURA 1. Localización de granitos rapakivi intruyendo rocas del Complejo Mitú reportados en el Departamento de Guainía, Colombia (modificado de López et al., 2007; INGEOMINAS, 2010; Cramer et al., 2011; López y Cramer, 2012)

\section{METODOLOGÍA}

Durante una salida de campo en la zona de estudio en cercanías a las comunidades indígenas de Danta y Matraca se tomaron datos y muestras de rocas en diferentes afloramientos de granitos rapakivi y rocas asociadas. En vista de la homogeneidad textural sólo cuatro muestras fueron seleccionadas (dos secciones de la zona de Danta y dos de la zona de Matraca) y preparadas como secciones delgadas y pulidas que fueron analizadas microscópicamente (Carl Zeiss, modelo AXIO SCOPE A1) incluyendo conteo de 300 puntos por sección para el análisis modal y una descripción detallada de las texturas presentes. Para determinar los elementos mayores y traza seis muestras fueron analizadas (tres de la Zona Danta y tres de la Zona Matraca) con el equipo de fluorescencia de rayos X, MagixPro PW - 2440 Phillips, en la Universidad Nacional de Colombia, Sede Bogotá (tubo de rodio, potencia máxima de $4 \mathrm{KW}$, límite de detección de elementos pesados metálicos $20 \mathrm{ppm}$ ), utilizando muestras pulverizadas y fundidas a perla.
De dos muestras obtenidas de los granitos rapakivi en la región (uno de la zona de Matraca y uno de la zona de Danta) fueron separados 120 circones mediante técnicas estandarizadas para montaje, los cuales fueron confeccionados con resina epoxi, desbastados y pulidos para una mejor exposición de los granos. La superficie de los montajes fue fotografiada y se tomaron imágenes de los circones por backscattering para un mejor posicionamiento del spot analítico. Las determinaciones realizadas mediante el método LA-ICP-MS siguieron el procedimiento descrito por Bühn et al. (2009), desafortunadamente los circones para la muestra de Danta presentaron mucho $\mathrm{Pb}$ común, dificultando la determinación de una edad para el granito en este sector.

Los análisis isotópicos fueron realizados usando un ICPMS Neptune (Thermo-Finnigan) acoplado con un Laser Ablation System (New Wave Research, USA) Nd-YAG $(\lambda=213 \mathrm{~nm})$, en el Laboratorio de Geología Isotópica de la Universidade Federal do Rio Grande do Sul. La ablación de los granos fue realizada en spots de $30 \mu \mathrm{m}$, con frecuencia de $10 \mathrm{~Hz}$ e intensidad de 0.19 a $1.02 \mathrm{~J} / \mathrm{cm}^{2}$. 
El material evaporado fue cargado por un flujo de $\mathrm{He}$ $(\sim 0.40 \mathrm{~L} / \mathrm{min})$ y $\operatorname{Ar}(\sim 0.90 \mathrm{~L} / \mathrm{min})$. En todos los análisis se utilizó un patrón GJ-1 para la corrección de la deriva del equipo, así como para el fraccionamiento entre los isótopos de $\mathrm{U}$ y $\mathrm{Pb}$, las desviaciones estándar son de $1 \sigma$. Las edades fueron calculadas utilizando ISOPLOT 3.0 (Ludwig, 2003) y los diagramas (95\% de confianza) fueron confeccionados en el mismo programa.

\section{GEOMORFOLOGIA}

Ya Huguett (1982) y Franco (1982) distinguieron cinco rasgos geomorfológicos principales en la región: inselberg, serranías, planicies selváticas, drenajes y zonas de inundación. Durante décadas los geomorfólogos han tratado de definir una edad y origen para las principales llanuras alrededor del mundo. Suramérica se ubica entre una de las mayores superficies de peniplanización conocida al igual que la Africana, con un espesor removido entre 1.000-1.500 m durante el Cretácico y Mioceno temprano (King, 1949), lo cual se correlaciona con el gran aporte de sedimentos durante este periodo a la cuenca cretácica y terciaria colombiana proveniente del Escudo de Guyana (Lamus et al., 2013; Horton et al., 2010; Bayona et al., 2008). Para el Cratón Amazónico se plantea un relieve policíclico donde varios ciclos de denudación (interrumpidos por eventos prolongados de levantamiento) dan inicio a un nuevo ciclo. Este proceso se ve reflejado en la formación de caídas de agua o rápidos en los principales ríos. Si observamos actualmente la configuración morfológica de los principales ríos del departamento de Guainía podemos plantear que se encuentra entre un ciclo de erosión avanzado en donde los raudales (p. ej. Payara, Zamuro, Danta, Cuale), son el producto del levantamiento que dio inicio a este ciclo y que renuevan la energía y capacidad del río para transportar estos sedimentos removidos cauce arriba. En tiempos futuros episodios de levantamientos del basamento darán inicio a otro ciclo.

La aparición de grandes serranías, posiblemente predeterminadas estructuralmente (Galvis et al., 1979), interrumpe la planicie selvática. Entre las más importantes están la Serranía del Naquén (río Guainía), Serranía de Caranacoa (río Inírida) y la Serranía de Mapiripana (río Guaviare), además de la presencia de cerros de forma dómica (p.ej. Cerro Mavicure, Mono, Pajarito, Danta y Lluvia) tipo "Inselberg" (Twidale, 1982; Campbell, 1997), conformados principalmente por granitoides de diferentes afinidades, entre ellos el granito rapakivi de Matraca y el granito rapakivi de Danta.

\section{GEOLOGÍA}

En el área de estudio, correspondiente a las márgenes del río Inírida en su cuenca media, existen algunos cerros pequeños aislados tipo "Inselberg" que presentan morfologías típicas de cuerpos intrusivos y no superan los $5 \mathrm{~km}^{2}$. En Cerro Lluvia, cerca de la comunidad indígena de Matraca en la margen norte del río y en Cerro Danta, frente a la comunidad indígena de Danta en la margen sur del río, afloran plutones con texturas rapakivi tipo piterlita (FIGURA 2). Inicialmente se interpretaron como unidades diferentes, pero sus características mineralógicas y geoquímicas nos permiten definirlos informalmente como granito rapakivi de Matraca (GRM). Estos granitos, junto a otros de características similares recientemente observados en el río Cuyari, pueden pertenecer a un periodo magmático Mesoproterozoico de mayor complejidad representado por pulsos sucesivos entre 1.400-1.300 Ma. Los cuerpos aflorantes en cercanías a la ciudad de Inírida, caño Chaquita (López et al., 2010 e INGEOMINAS, 2010) podrían tener mayor relación con el Granito de Parguaza por su proximidad (FIGURA 1).

\section{Granito rapakivi de Matraca}

En Cerro Lluvia aflora un cuerpo intrusivo de composición granítica y textura rapakivi tipo piterlita, masivo, poco fracturado y disectado, que conforma un cerro dómico aislado de escasa altitud. En su base se encuentra esta roca ígnea de textura rapakivi, holocristalina e inequigranular, que contiene cristales ovoides de feldespato alcalino y fenocristales de biotita de tamaño de grano muy grueso (hasta $2 \mathrm{~cm}$ ) (FIGURA 3C Y D), los afloramientos presentan un bajo grado de meteorización. Hacia la cima del cerro con una altura máxima de 175 m.s.n.m. se observa macroscópicamente la misma textura rapakivi con meteorización esferoidal local. En general este cuerpo granítico sin variación textural está compuesto por cuarzo (25-27\%), feldespato alcalino (22-31\%), albita-oligoclasa $(43-50 \%)$ y biotita $(3-7 \%)$. Como minerales opacos predominan magnetitas e ilmenitas con inclusiones de minerales ricos en $\mathrm{Nb}$, $\mathrm{U}$, Th y REE.

Solamente escasas venas de cuarzo y feldespato alcalino cortan el GRM en Cerro Lluvia con espesor variable que no supera los $5 \mathrm{~cm}$ (FIGURA 3A); estas venas disminuyen su espesor hacia los extremos en forma de lente. Depósitos coluviales y regolitos de hasta $15 \mathrm{~cm}$ de espesor en la base del cerro contienen cantidades considerables de minerales metálicos de interés como ilmenitas con inclusiones enriquecidas en $\mathrm{Nb}, \mathrm{U}, \mathrm{Th}$ y REE similares a los encontrados en la roca in-situ que serán descritos más adelante. 


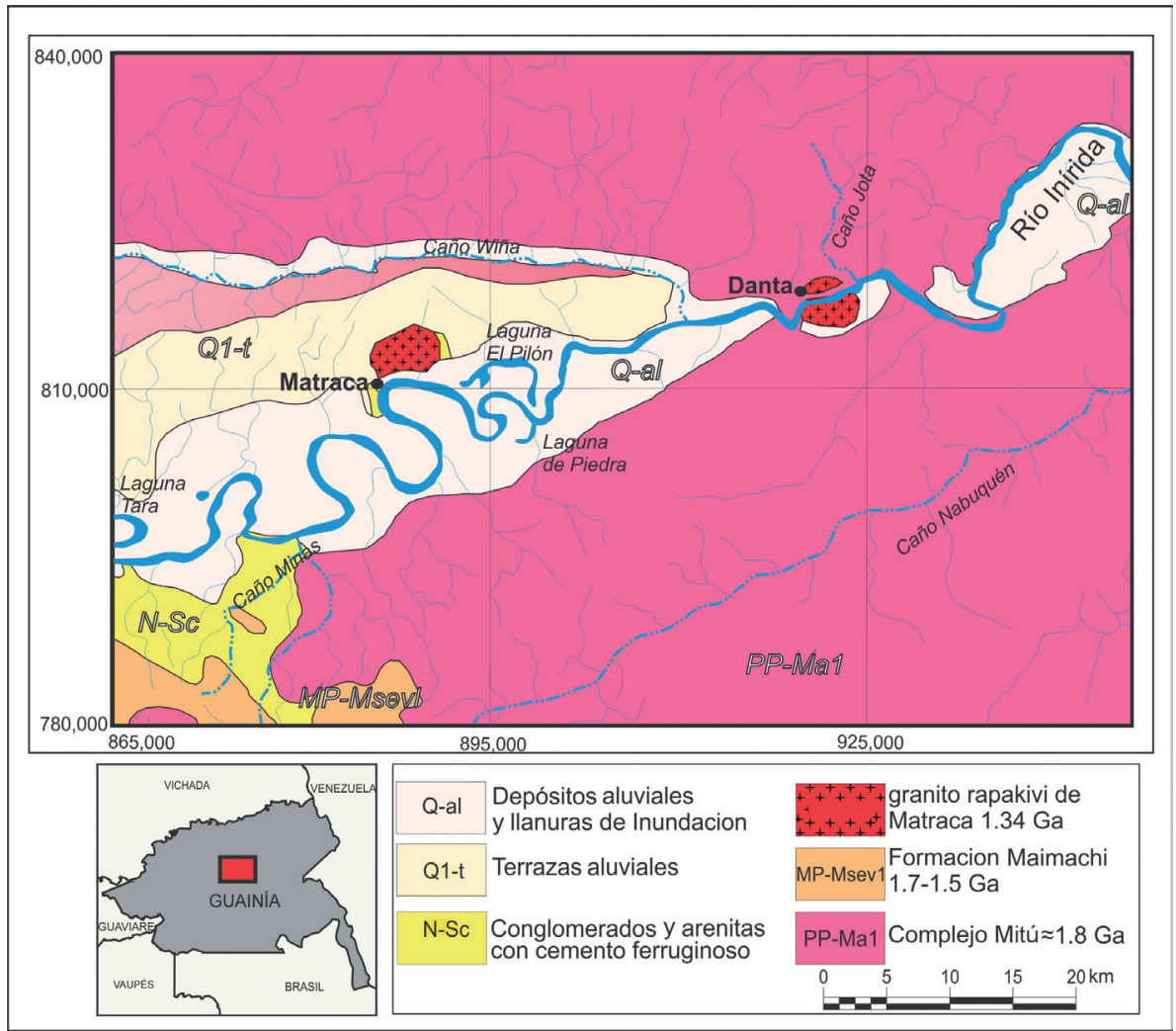

FIGURA 2. Mapa geológico del área de estudio sobre el Río Inírida, Departamento de Guainía (modificado de INGEOMINAS, 2002 e INGEOMINAS, 2010).
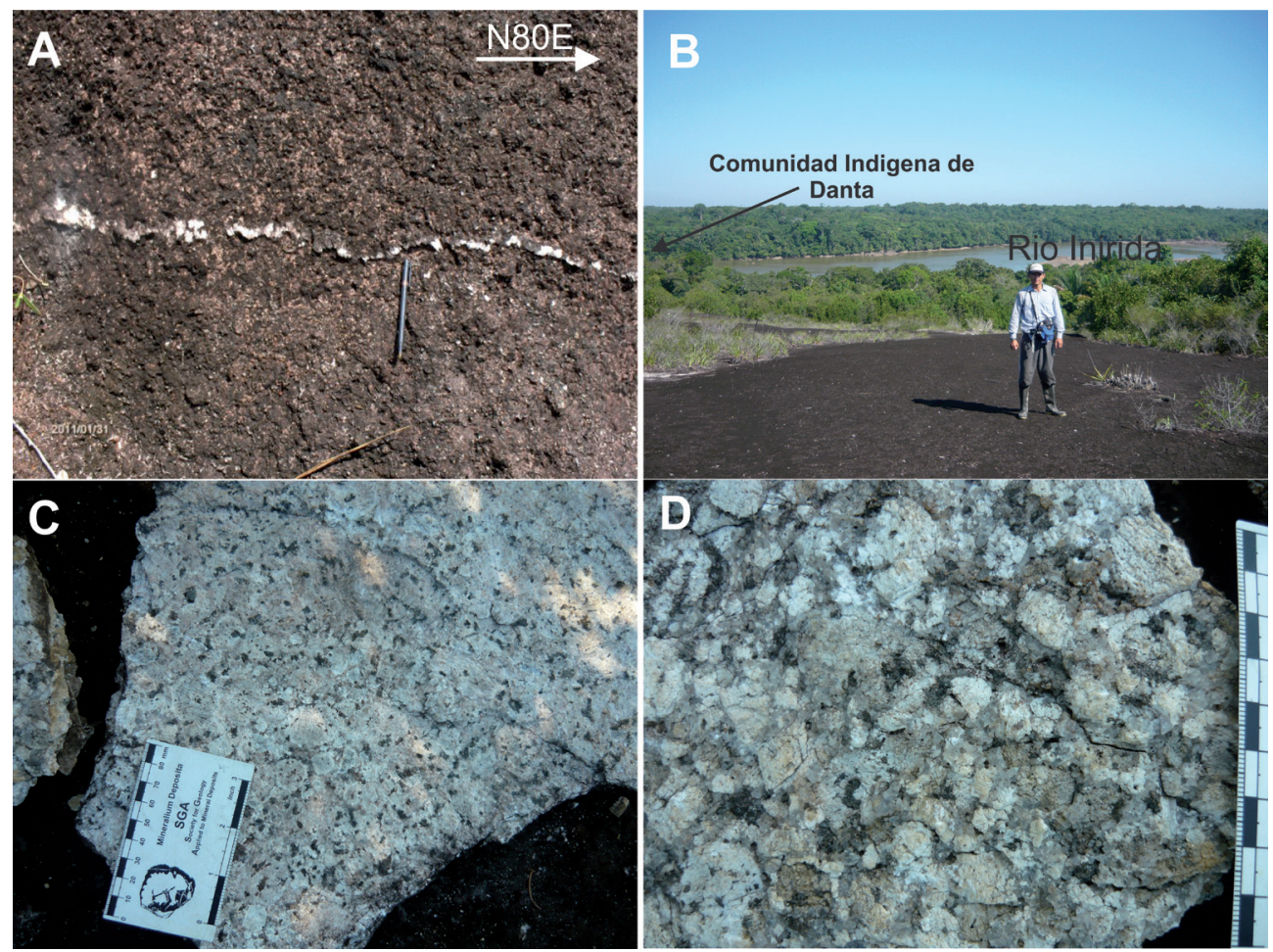

FIGURA 3. A) vena de cuarzo en Cerro Lluvia. B) afloramiento en cercanías a la Comunidad Indígena de Danta. C) y D) textura rapakivi tipo piterlita del granito rapakivi de Matraca. 
En el flanco sur del río Inírida, cerca de la comunidad indígena de Danta, aflora al lado del raudal Danta un cuerpo granítico como un cerro de forma redondeada (FIGURA 3B) y algo alargado hacia el E, en partes cortado por diques pegmatíticos y algunos diques lenticulares de cuarzo, con características mineralógicas similares a las expuestas en Cerro Lluvia en cuanto a textura rapakivi tipo piterlita, masivo, sin fracturas o diaclasas y con meteorización esferoidal superficial. En el flanco sur, hacia su base, discurre un pequeño caño, que acumula gran cantidad de minerales de interés económico de $\mathrm{Nb}$ y REE semejantes a los encontrados en los depósitos aluviales de Cerro Lluvia con tamaños arena gruesa a media y fragmentos poco redondeados de minerales como cuarzo, biotita, moscovita y feldespato alcalino.

\section{Rocas Sedimentarias}

En la intersección con Caño Lluvia puede observarse una cobertura sedimentaria yaciendo discordantemente sobre el GRM. Esta cobertura sedimentaria fuertemente alterada que aflora en pequeñas partes, muestra un comportamiento bastante friable y en el Atlas Geológico Colombiano a escala 1:500.000 (Gómez et al., 2007) es denominada como N-Sc (Conglomerados y arenitas con cemento ferruginoso). En esta parte del área de estudio, las sedimentitas están conformadas por capas medias a gruesas de sub-litoarenitas conglomeráticas con gránulos y guijos de cuarzo lechoso (49\%) y líticos $(6 \%)$, y la matriz (40\%) constituye un cemento ferruginoso (hematita), los clastos son redondeados a sub-redondeados y el porcentaje de poros es alto (5\%) (FIGURA4). Los fragmentos líticos son en su totalidad de origen metamórfico lo que indica que provienen de rocas del basamento. Los sedimentos permiten interpretar un origen continental y de correlación con rocas descritas en otras localidades del oriente colombiano como del Terciario. Esta misma roca sedimentaria también aflora en el puerto de la comunidad indígena de Matraca, donde presenta pequeños afloramientos de 2 a $3 \mathrm{~m}^{2}$.
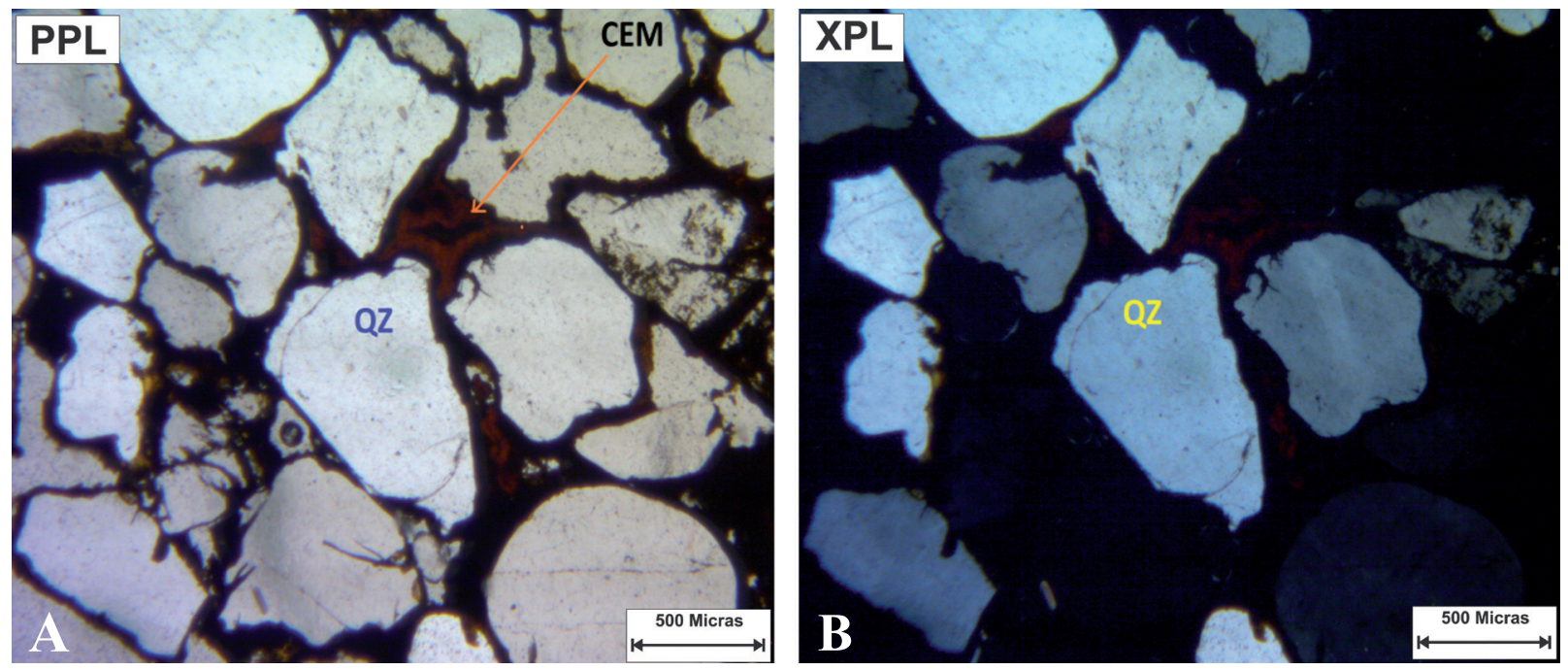

FIGURA 4. Microfotografía de sub-litoarenita de N-Sc en sección delgada A. PPL, B. XPL (QZ=cuarzo, CEM=Cemento).

\section{PETROGRAFÍA DE LOS GRANITOS RAPAKIVI}

\section{Composición Modal y Clasificación}

Los granitos rapakivi presentan principalmente fenocristales ovoides a tabulares de feldespato alcalino embebidos en una matriz fanerítica conformando así una textura bimodal (porfirítica). Se distinguen algunas texturas específicas como rapakivi, mirmequítica, antipertítica, pertítica y poiquilítica; los cristales no han sufrido deformación y pueden alcanzar tamaños mayores a $1 \mathrm{~cm}$, especialmente los de feldespato alcalino y biotita. Son rocas ígneas holocristalinas ácidas, en su mayoría inequigranulares (porfirítica) y leucocráticas, cuyo tamaño de los cristales varía de medio a grueso (1-5mm). Están compuestas principalmente por cuarzo, feldespato alcalino (microclina-ortoclasa), plagioclasa (albita-oligoclasa) y biotita (FIGURA 5). Entre los minerales accesorios, se identificaron opacos como magnetitas e ilmenitas, además de moscovita, circones euhedrales (FIGURA 5), turmalinas y esfenas. En el triángulo QAP de clasificación de Streckeisen (1967) (FIGURA 6), se grafican en los campos de Monzogranitos a Granodioritas. 

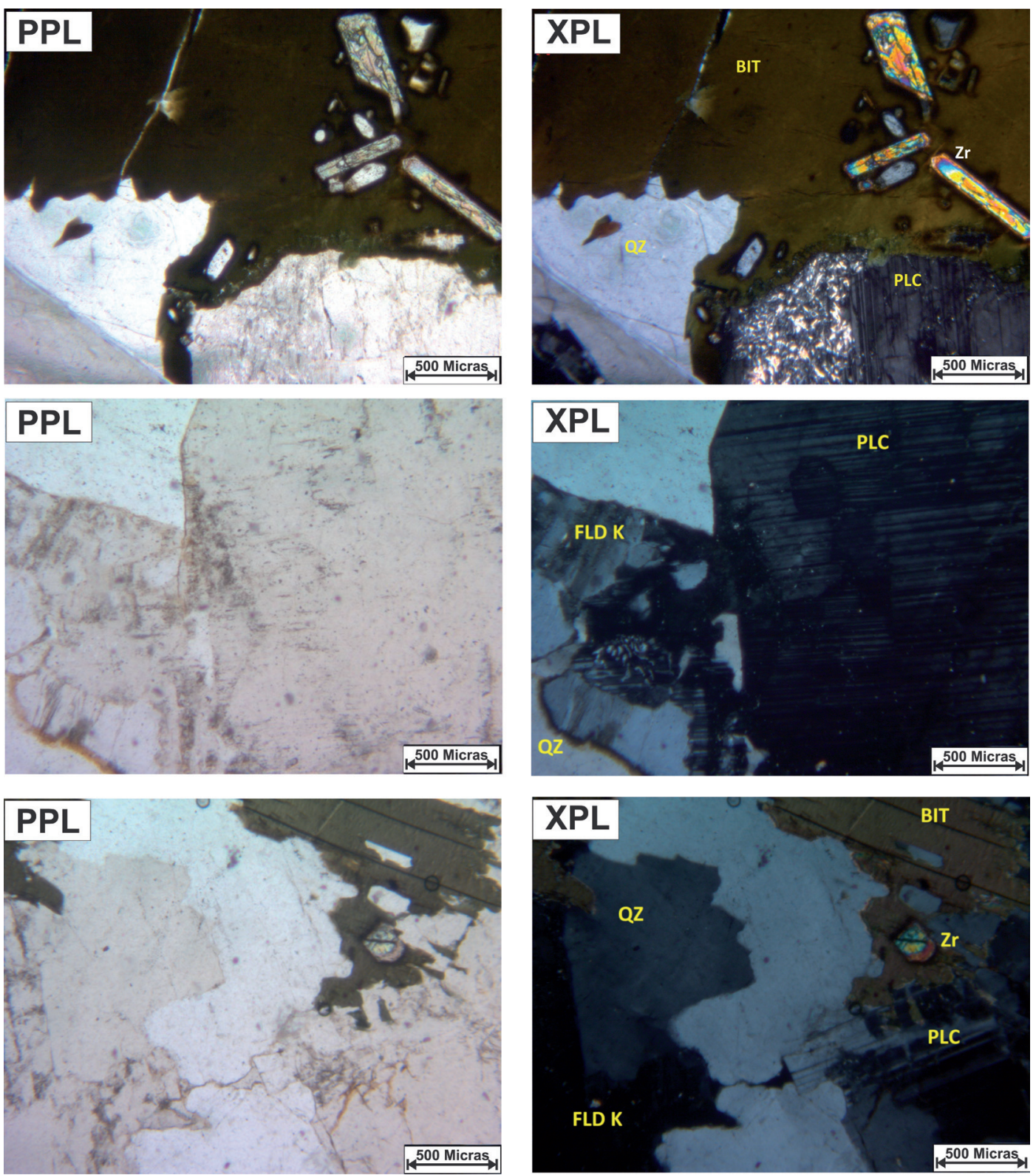

FIGURA 5. Microfotografía de monzogranitos del granito rapakivi de Matraca en sección delgada (QZ=cuarzo, FLD K= feldespatos potásicos, $\mathrm{PLC}=$ plagioclasas, $\mathrm{BIT}=$ biotita, $\mathrm{MCV}=$ moscovita, $\mathrm{Zr}=$ Circón). A. XPL, B. PPL

\section{Aspectos mineralógicos de la textura rapakivi}

El feldespato alcalino y la biotita se presentan como fenocristales subhedrales de tamaño de grano medio, las plagioclasas se encuentran como cristales euhedrales a subhedrales bastante sericitizados con un ángulo de extinción de $5^{\circ}$ e intercrecimiento de feldespato alcalino formando textura antipertítica. También se observa textura mirmequítica de feldespatos alcalinos con macla de microclina e intercrecimiento de cuarzo (FIGURA 6), además algunos feldespatos presentan textura poiquilítica.
En el caso del granito rapakivi de Matraca, la textura rapakivi fue formada por la exsolución de albita de la microclina ovoide y su migración hacia los bordes del grano. Se presume que en los granitos rapakivi la composición de la aureola rapakivi es similar a la de las plagioclasas presentes en la matriz, y que la albita exsuelta, al no tener tendencia a producir aureolas de oligoclasa entorno a los ovoides de feldespato alcalino, forma la albita intersticial y las aureolas de mirmequita (Rämö and Haapala, 1995) -presentes en las muestras. A pesar que se han formulado muchos mecanismos 
para explicar el desarrollo de la textura rapakivi (e.g. Rämö and Haapala, 1995; Eklund and Shebanov, 1999; Haapala and Rämö, 1999), los cambios composicionales por mezcla de magmas de diferente composición, habrán sido un mecanismo muy importante para el magmatismo en la parte NW del Cratón Amazónico. Esta idea se soportaría al identificar en los granitos rapakivi de la cuenca media del río Inírida una asociación magmática bimodal, así como enclaves microgranulares máficos (p. ej. en los granitoides tipo Rapakivi en cercanías a la ciudad de Inírida -López et al., 2010, e INGEOMINAS, 2010), y diques sin-plutónicos.

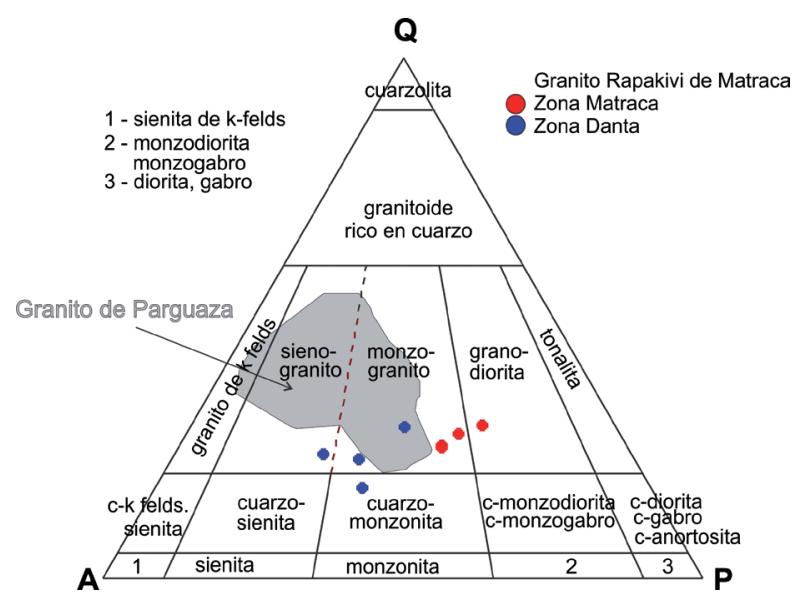

FIGURA 6. Clasificación del granito rapakivi Matraca en el diagrama Streckeisen (1967).

\section{GEOQUÍMICA}

Geoquímicamente el GRM (TABLA 2) contiene concentraciones no muy elevadas de $\mathrm{SiO}_{2}(60.8 \%$ a $68.8 \%$ ) para rocas ácidas, pero si altos contenidos en álcalis total $\left(\mathrm{Na}_{2} \mathrm{O}+\mathrm{K}_{2} \mathrm{O} 7 \%\right.$ a $\left.10 \%\right), \mathrm{Al}_{2} \mathrm{O}_{3}(13.10 \%$ a $16.39 \%$ ) y $\mathrm{FeOT} / \mathrm{FeOT}+\mathrm{MgO}(0.95 \%)$. Así mismo, su baja concentración de $\mathrm{MgO}(0.2 \%$ a $0.55 \%)$ y $\mathrm{CaO}$ $(0.9 \%$ a $2.6 \%)$ concuerda con los granitos rapakivi evolucionados a partir de magmas tipo A (Rämö and Haapala, 1995).

En el diagrama $\mathrm{Na}_{2} \mathrm{O}+\mathrm{K}_{2} \mathrm{O}$ vs $\mathrm{SiO}_{2}$ de Middlemost (1985), las muestras analizadas del GRM se encuentran dentro del campo de las cuarzo-monzonitas por su contenido en $\mathrm{SiO}_{2}(<70 \%)$ sin alcanzar el campo de granito sensu stricto (FIGURA 7). Dentro del diagrama $\mathrm{A} / \mathrm{CNK}\left(\mathrm{Al}_{2} \mathrm{O}_{3} /\left(\mathrm{CaO}+\mathrm{Na}_{2} \mathrm{O}+\mathrm{K}_{2} \mathrm{O}\right)_{{ }_{\text {mol }}}\right)$ vs $\mathrm{A} / \mathrm{NK}$ $\left(\mathrm{Al}_{2} \mathrm{O}_{3} /\left(\mathrm{Na}_{2} \mathrm{O}+\mathrm{K}_{2} \mathrm{O}\right)_{\text {mol. }}\right)$ según Shand (1943) (FIGURA 7), las rocas del GRM son ploteadas notablemente en el campo de los granitos metaluminosos a peraluminosos y con un índice agpatico (relación molecular $\mathrm{K}_{2} \mathrm{O}+\mathrm{Na}_{2} \mathrm{O}$ /
$\mathrm{A}_{2} \mathrm{O}_{3}$ ) variando desde $0.49 \%$ a $0.63 \%$, ubicándose en el límite alcalino-subalcalino similar a lo reportado para otros granitos rapakivi a nivel mundial (Rämö and Haapala, 2005, Rämö and Haapala, 1995). Su alta relación $\mathrm{FeOT} / \mathrm{FeOT}+\mathrm{MgO}(>0.8)$ lo hacen un granito ferroso y sus valores de $\mathrm{Na}_{2} \mathrm{O}+\mathrm{K}_{2} \mathrm{O}-\mathrm{CaO}(>4 \%)$, en relación con su contenido de $\mathrm{SiO}_{2}$, le atribuyen una tendencia alcalina a alcalino-cálcica. Por sus valores de $\mathrm{K}_{2} \mathrm{O}(>4 \%)$ en el diagrama $\mathrm{K}_{2} \mathrm{O}$ vs $\mathrm{SiO}_{2}$, según Peccerillo and Taylor (1976), se encuentran dentro del campo de la serie shoshonítica.

TABLA 2. Composición geoquímica del GRM (óxidos de elementos mayores en \% y elementos traza en ppm, <ld: por debajo del límite de detección de 20 ppm del equipo FRX).

\begin{tabular}{|c|c|c|c|c|c|c|}
\hline Muestra & $\begin{array}{c}\text { Matraca } \\
1\end{array}$ & $\begin{array}{c}\text { Matraca } \\
2\end{array}$ & $\begin{array}{c}\text { Matraca } \\
3\end{array}$ & $\begin{array}{c}\text { Danta } \\
1\end{array}$ & $\begin{array}{c}\text { Danta } \\
2\end{array}$ & $\begin{array}{c}\text { Danta } \\
3\end{array}$ \\
\hline $\mathrm{SiO}_{2}$ & 68,88 & 66,02 & 67 & 66,51 & 64,06 & 60,81 \\
\hline $\mathrm{Al}_{2} \mathrm{O}_{3}$ & 14,5 & 15,56 & 16,37 & 16,39 & 15,75 & 13,1 \\
\hline $\mathrm{Fe}_{2} \mathrm{O}_{3} \mathrm{t}$ & 4,89 & 5,06 & 3,69 & 3,72 & 6,85 & 9,58 \\
\hline $\mathrm{MnO}$ & 0,06 & 0,07 & 0,06 & 0,06 & 0,12 & 0,08 \\
\hline $\mathrm{MgO}$ & 0,31 & 0,24 & 0,21 & 0,25 & 0,46 & 0,55 \\
\hline $\mathrm{CaO}$ & 1,39 & 2,64 & 1,31 & 1,3 & 2,66 & 0,95 \\
\hline $\mathrm{Na}_{2} \mathrm{O}$ & 2,83 & 3,81 & 3,29 & 3,16 & 3,47 & 1,8 \\
\hline $\mathrm{K}_{2} \mathrm{O}$ & 5,81 & 5,01 & 6,76 & 7,22 & 4,24 & 5,71 \\
\hline $\mathrm{TiO}_{2}$ & 0,39 & 0,43 & 0,34 & 0,32 & 0,72 & 0,55 \\
\hline $\mathrm{P}_{2} \mathrm{O}_{5}$ & 0,1 & 0,276 & 0,057 & 0,107 & 0,171 & 3,518 \\
\hline LOI & 0,4295 & 0,44791 & 0,49381 & 0,54113 & 1,0452 & 3,06159 \\
\hline $\mathrm{Ba}$ & 1576,4 & 1871,9 & 1791,3 & 1845,1 & 1630,1 & 1307,7 \\
\hline $\mathrm{Sr}$ & 228,3 & 262,1 & 252,3 & 270,6 & 186 & 180 \\
\hline $\mathrm{Y}$ & 63 & 94,5 & 23,6 & 15,7 & 95 & 31,5 \\
\hline $\mathrm{Zr}$ & 873,6 & 1502,8 & 747,7 & 644,1 & 1954,4 & 636,7 \\
\hline $\mathrm{Cr}$ & $<$ ld & $<\mathrm{ld}$ & 287,4 & $<\mathrm{ld}$ & $<\mathrm{ld}$ & $<\mathrm{ld}$ \\
\hline $\mathrm{Zn}$ & 64,3 & 112,5 & 104,4 & 109,1 & 136,6 & 80,3 \\
\hline $\mathrm{Ni}$ & 204,3 & 172,9 & 573,7 & 117,9 & 212,1 & 157,2 \\
\hline $\mathrm{Rb}$ & 347,5 & 274,3 & 411,5 & 429,8 & 246,9 & 374,9 \\
\hline $\mathrm{Nb}$ & 41,9 & 69,9 & $<\mathrm{ld}$ & $<\mathrm{ld}$ & 76,9 & $<\mathrm{ld}$ \\
\hline Th & $<$ ld & $<\mathrm{ld}$ & $<$ ld & 210,9 & $<\mathrm{ld}$ & $<\mathrm{ld}$ \\
\hline $\mathrm{Ce}$ & 594,3 & $<\mathrm{ld}$ & $<$ ld & 447,7 & $<\mathrm{ld}$ & $<\mathrm{ld}$ \\
\hline $\mathrm{Cu}$ & 111,4 & $<\mathrm{ld}$ & $<\mathrm{ld}$ & 127,8 & $<$ ld & 135,8 \\
\hline
\end{tabular}



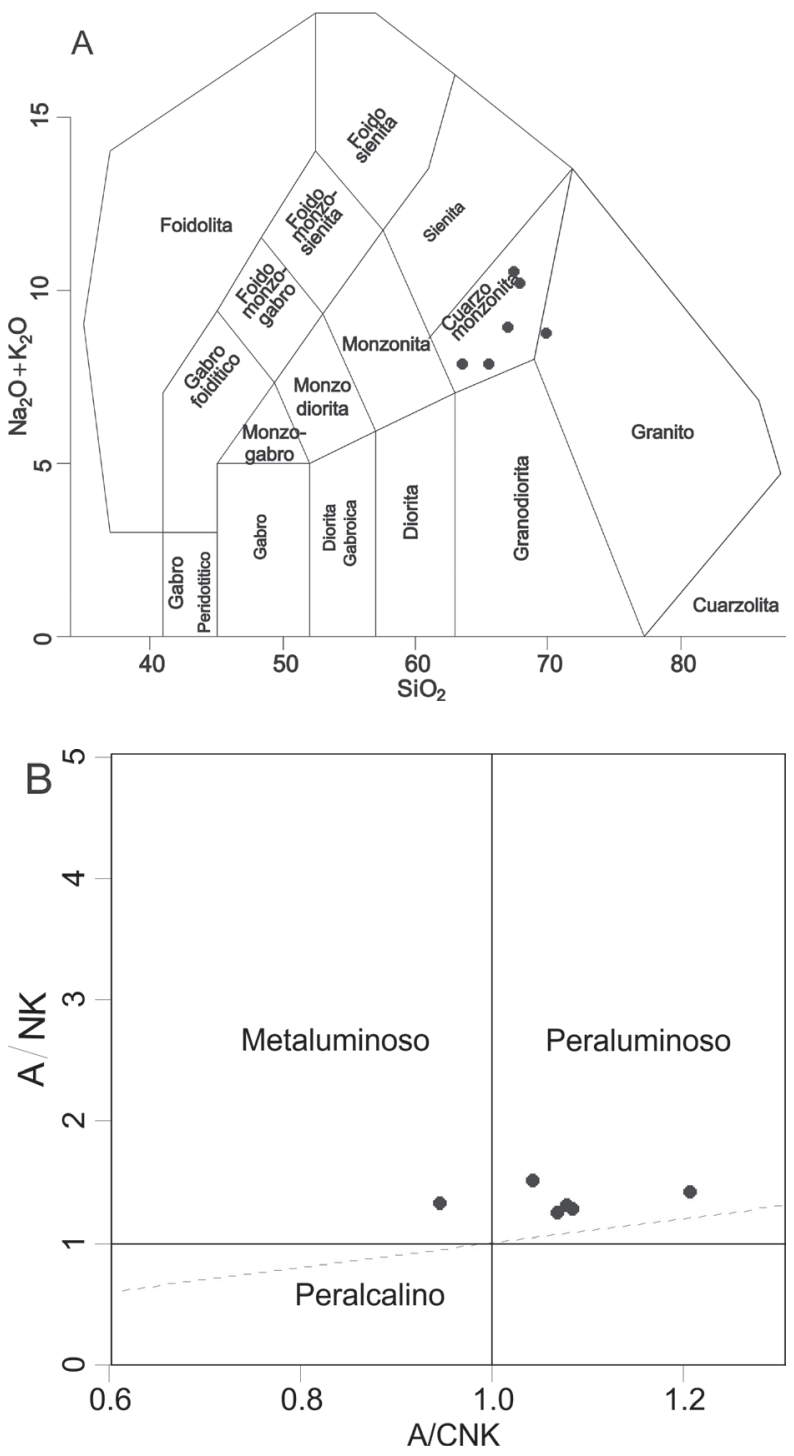

FIGURA 7. Rocas del GRM representadas en los diagrama A. $\mathrm{Na}_{2} \mathrm{O}+\mathrm{K}_{2} \mathrm{O} v s \mathrm{SiO}_{2}$ de Middlemost (1985) y B. A/CNK vs A/ NK de Shand (1943).

\section{Afinidad Tectónica}

Loiselle and Wones (1979) introducen el concepto de granitos tipo A para designar granitos anorogénicos y de naturaleza alcalina. Los granitos tipo A son caracterizados geoquímicamente por presentar valores elevados de $\mathrm{SiO}_{2}$ (70\%), Fe/Mg, Zr, Nb, Y, Ga, y ETR, a excepción del Eu, y bajos contenidos de $\mathrm{CaO}$, $\mathrm{MgO}, \mathrm{Ba}$ y $\mathrm{Sr}$ (Whalen et al., 1987). Su origen fue explicado inicialmente por dos modelos. El primero responsabilizaba una fusión parcial de corteza granulítica residual (Collins et al., 1982), mientras el segundo los admitía como resultado de la cristalización fraccionada de magmas basálticos alcalinos (Eby, 1992).

Por muchas de sus características, el GRM es también compatible con los granitos tipo I, su carácter metaluminoso a peraluminoso, mediano y restringido contenido de $\mathrm{SiO}_{2}$ (60-70\%), alto contenido de $\mathrm{K}_{2} \mathrm{O}+\mathrm{Na}_{2} \mathrm{O}, \mathrm{Zr}$, Nb y su alta razón $\mathrm{K}_{2} \mathrm{O} / \mathrm{Na}_{2} \mathrm{O}$ (entre $1 \mathrm{y}$ 2); pero al final presenta más afinidad con los granitos tipo A por la presencia de Fe-biotita y magnetita, su tendencia subalcalina y alta relación $\mathrm{Fe} / \mathrm{Mg}$. He aquí que las rocas del GRM representadas en los diagramas $\mathrm{FeOt} / \mathrm{MgO}$ vs $\mathrm{Zr}+\mathrm{Nb}+\mathrm{Ce}+\mathrm{Y}$ y $\left(\mathrm{Na}_{2} \mathrm{O}+\mathrm{K}_{2} \mathrm{O}\right) / \mathrm{CaO}$ vs $\mathrm{Zr}+\mathrm{Nb}+\mathrm{Ce}+\mathrm{Y}$, según Whalen et al. (1987), se encuentren notablemente en el campo de los granitos tipo A (FIGURA 8).
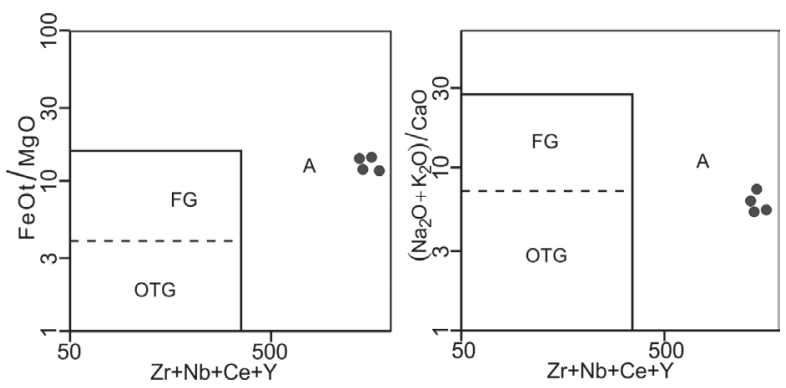

FIGURA 8. Representación del GRM dentro del campo de granitos tipo $\mathrm{A}$ en los diagramas $\mathrm{FeOt} / \mathrm{MgO}$ vs $\mathrm{Zr}+\mathrm{Nb}+\mathrm{Ce}+\mathrm{Y}$ $\mathrm{y}\left(\mathrm{Na}_{2} \mathrm{O}+\mathrm{K}_{2} \mathrm{O}\right) / \mathrm{CaO}$ vs $\mathrm{Zr}+\mathrm{Nb}+\mathrm{Ce}+\mathrm{Y}$ de Whalen et al. (1987).

Los diagramas de $\mathrm{Nb}$ vs $\mathrm{Y}$ y $\mathrm{Rb}$ vs $\mathrm{Y}+\mathrm{Nb}$ de Pearce et al., (1984), muestran como el GRM se encuentra notablemente dentro del campo de los granitos intraplaca (WPG) (FIGURA 9). Dentro del diagrama $\mathrm{R} 2=6 \mathrm{Ca}+2 \mathrm{Mg}+\mathrm{Al} v s \mathrm{R} 1=4 \mathrm{Si}-11(\mathrm{Na}+\mathrm{K})$ $-2(\mathrm{Fe}+\mathrm{Ti})$ de Batchelor and Bowden (1985), estas rocas graníticas se encuentran dentro del campo de granitos tardíos post-colisionales a anorogénicos (FIGURA 9).

La relación Fetotal/(Fetotal $+\mathrm{MgO})$ vs $\mathrm{SiO}_{2}$, según Frost et al. (2001), utilizada para clasificar los granitoides con base en su historia de diferenciación magmática, pone el granito rapakivi de Matraca notablemente en el campo de los granitos ferrosos (FIGURA 10), característica que distingue a los granitos tipo A de los relacionados con procesos orogenéticos como en las cordilleras (Frost et al., 2001; Rämö and Haapala, 2005). 

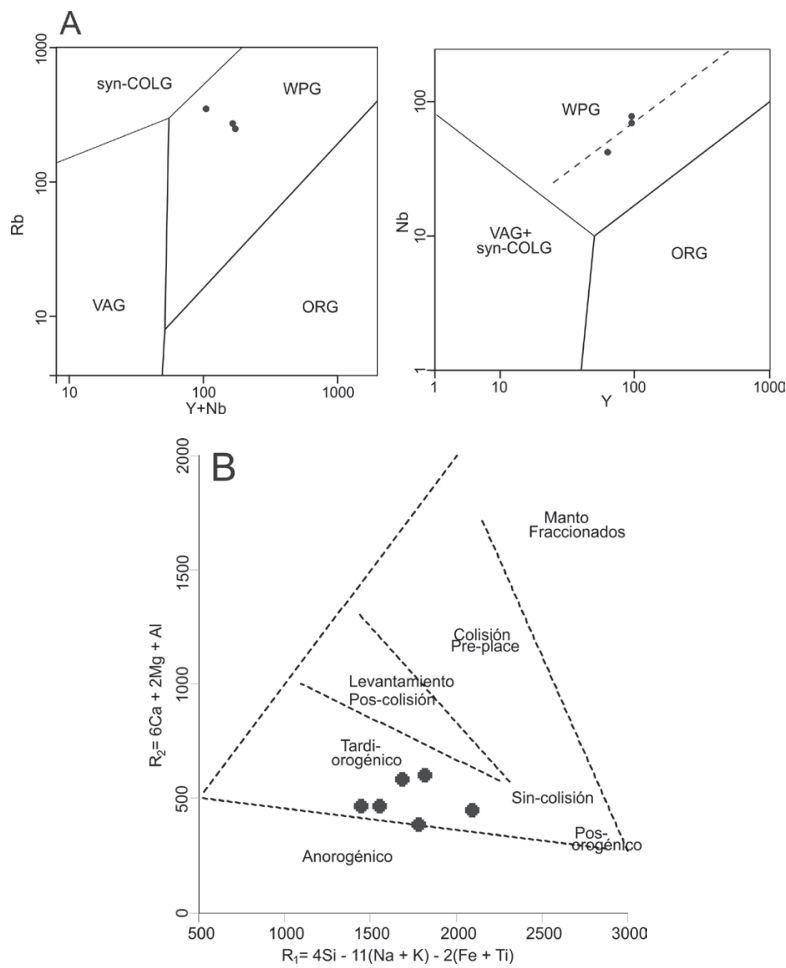

FIGURA 9. GRM dentro de los diagramas A. Rb vs $\mathrm{Y}+\mathrm{Nb}$ y de $\mathrm{Nb} v s$ Y de Pearce et al., (1984); y B. diagrama R2 $=6 \mathrm{Ca}+$ $2 \mathrm{Mg}+\mathrm{Al} v s \mathrm{R} 1=4 \mathrm{Si}-11(\mathrm{Na}+\mathrm{K})-2(\mathrm{Fe}+\mathrm{Ti})$ de Batchelor and Bowden (1985).

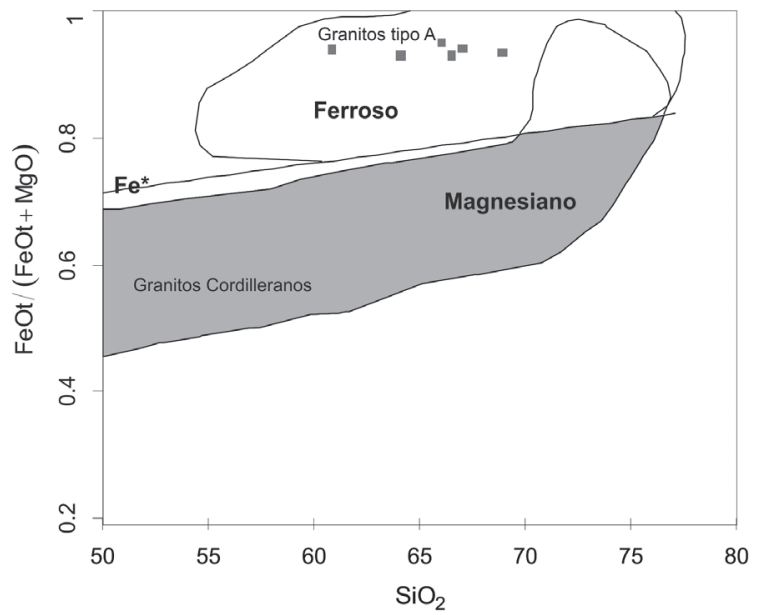

FIGURA 10. Carácter ferroso de GRM según el diagrama Fetotal/(Fetotal+MgO) vs $\mathrm{SiO}_{2}$ de Frost et al. (2001).

\section{GEOCRONOLOGÍA}

Los circones extraídos del granito rapakivi de Matraca con tamaños entre 120-350 micras no presentan zonación (FIGURA 11), pero muchos de ellos son metamícticos, fracturados y con inclusiones que fueron descartados para las dataciones por la probable pérdida de isótopos de $\mathrm{U}$, Th o $\mathrm{Pb}$ y así crear datos no confiables. Los datos isotópicos (TABLA 3) representan una edad concordante obtenida para el granito rapakivi de Matraca es de 1.343 +/- 8 Ma (FIGURA 12).
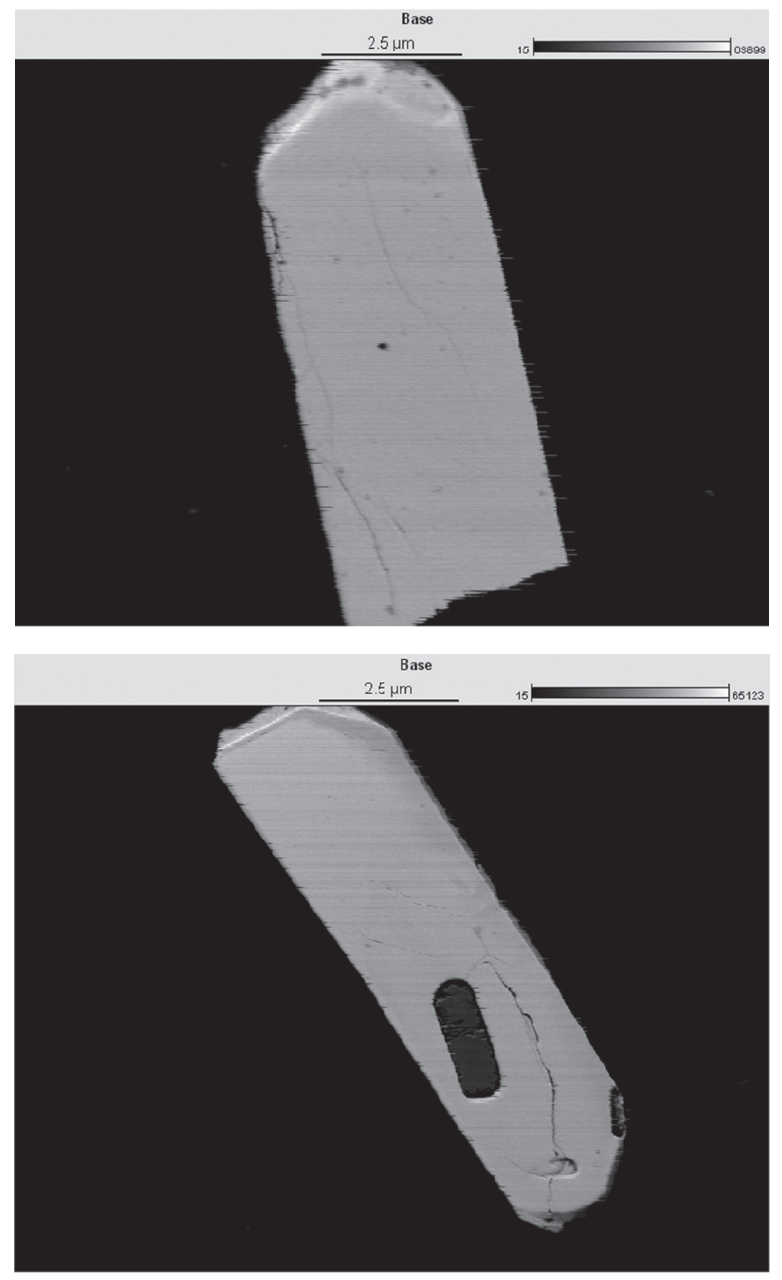

FIGURA 11. Microfotografías por BSE de los circones ígneos del GRM utilizados para la obtención de edades $\mathrm{U} / \mathrm{Pb}$ (nótese algunas de las inclusiones presentes en la imagen inferior).

\section{OCURRENCIAS MINERALES}

Obviamente asociadas a estos dos cuerpos graníticos de textura rapakivi (Matraca y Danta) se encuentran ocurrencias minerales con contenidos importantes de $\mathrm{Nb}$, U y REE. En depósitos coluviales se encontraron ilmenitas de $1-5 \mathrm{~mm}$ de longitud con exsoluciones de magnetita y que poseen valores anómalos de $\mathrm{Nb}$ hasta 2\% (FIGURA 13). Éstos también fueron encontrados dentro de la roca granítica como minerales accesorios, y posteriormente se determinó que los valores anómalos de $\mathrm{Nb}$ están relacionados a inclusiones micrométricas de lo que se ha clasificado inicialmente como minerales del grupo del pirocloro, por presentar además de $\mathrm{Ca}$ valores anómalos de $\mathrm{Yb} 4.58, \mathrm{U} 2.7 \%$ y $\mathrm{Th} 0.6 \%$ 
(Bonilla et al., 2010; Cramer et al., 2010a,b; Cramer et al., 2011). Sin embargo, los análisis puntuales sobre estas inclusiones muestran valores de $\mathrm{Nb}$ cercanos a
$7 \%$, con lo cual es improbable que correspondan a pirocloro ya que éstos comúnmente presentan valores modales cercanos a $50 \%$.

TABLA 3. Resultados isotópicos de U/Pb para las muestras analizadas del granito rapakivi de Matraca.

\begin{tabular}{|c|c|c|c|c|c|c|c|c|c|c|c|c|c|c|c|c|c|}
\hline Mue & $\begin{array}{c}f(206) \\
\%\end{array}$ & Th/U & $\begin{array}{c}6 / 4 \\
\text { ratio }\end{array}$ & $\begin{array}{c}7 / 6 \\
\text { ratio }\end{array}$ & $\begin{array}{l}1 \mathrm{~s} \\
(\%)\end{array}$ & $\begin{array}{c}7 / 5 \\
\text { ratio }\end{array}$ & $\begin{array}{c}1 \mathrm{~s} \\
(\%)\end{array}$ & $\begin{array}{c}6 / 8 \\
\text { ratio }\end{array}$ & $\begin{array}{l}1 \mathrm{~s} \\
(\%)\end{array}$ & Rho & $\begin{array}{l}7 / 6 \\
\text { age }\end{array}$ & $\begin{array}{c}1 \mathrm{~s} \\
(\mathbf{M a})\end{array}$ & ge & $\begin{array}{c}1 \mathrm{~s} \\
(\mathbf{M a})\end{array}$ & $\begin{array}{l}6 / 8 \\
\text { age }\end{array}$ & $\begin{array}{c}1 \mathrm{~s} \\
(\mathrm{Ma})\end{array}$ & $\begin{array}{c}\text { Conc } \\
(\%)\end{array}$ \\
\hline & & & & & & & & & & 92 & 8 & 9,6 & 8 & 6 & 8 & 1,4 & \\
\hline & & & & & 0,5 & & 1,1 & & & 9 & & 9 & & 8,5 & 5 & & 101,43 \\
\hline & & 0 & & & 0 & & 2 & & 2 , & 0,96 & 36,7 & 12,5 & 56,7 & 16,4 & 1362,9 & 25,8 & 01 \\
\hline & & 0 & & ? & 0 & & 1,8 & & & 1 & 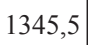 & & & 1 & 10. & 24 & \\
\hline & & 0 , & & & 0 , & 6 & 1,2 & & 1 & 0,94 & 1315,1 & 9,7 & 344,9 & 8,6 & 1363,8 & 12,8 & 103 \\
\hline & & & & & 0 & & 2 & & 2 & 99 & 22,7 & 3 & 2,1 &, 5 & 54,3 & 8 & \\
\hline 21 & 0 & 0,02 & 256 & 8631 & 0,6 & 28.097 & 2,6 & 0 & 2 , & 0,97 & 1345,2 & 11,2 & 1358,1 & 19,4 & 1366,4 & 31,1 & 101,57 \\
\hline & & 0,01 & & 697 & 0 , & & 1,7 & & 1,7 & 0,96 & 1359,9 & 8,7 & 6,5 & 13 & 1370,7 & 20,6 & 8 \\
\hline & & 0 & & 0 & 0 , & 2 & 2 & 0 & 2 & 0,99 & 132 & 1 & 132 & 18 & 131 & 2 & 99,15 \\
\hline & & 0,0 & 71 & 528 & 0,6 & 72 & 2,2 & 278 & 2,1 & 0,96 & 1322 & 12,6 & 1338,6 & 16,5 & 1349,1 & 25,9 & 102,05 \\
\hline & & 0 & & 0,08666 & 0 , & 7 & 1 , & 898 & 1 , & 0,96 & 1353 & 12,3 & 1370,3 & 13 & 1381,4 & 19 & 102,1 \\
\hline M1160_ & 1 , & & & 8616 & 0,6 & 33 & 1,2 & 12 & 1,1 & 0,86 & 134 & 12 & 9 & 9,2 & 1314,1 & 12,8 & 98 \\
\hline MT & 0,03 & 0,01 & 105572 & 0,08678 & 1 , & 27.694 & 1,9 & 0,23022 & 1, & 0,75 & 1357,6 & 24,6 & 1346,9 & 14,7 & 1339 & 18,4 & 98,73 \\
\hline MT160_31-1 & 0 , & 0 & 349 & 08556 & 0 , & 810 & 2,4 & 26 & 2,3 & 0,99 & 132 & 8 & 132 & 17,8 & 1320,1 & 27,9 & 99,39 \\
\hline MT160_46 & 0,07 & 0 & 522 & 0,0862 & 0,5 & 7.845 & 1,8 & 341 & 1,6 & 0,98 & 1343,1 & 10 & 1353 & 13,7 & 1366,5 & 19 & 101,02 \\
\hline
\end{tabular}

Discordantes - perdida $\mathrm{Pb}$ - desconsiderados del cálculo de la concórdia

\begin{tabular}{l|l|l|l|l|l|l|l|l|l|l|l|l|l|l|l|l|l}
\hline MT160_12 & 0,71 & 0,01 & 2479 & 0,08351 & 0,9 & 13.798 & 3,2 & 0,11984 & 3,1 & 0,98 & 1281,1 & 18 & 880,3 & 19,1 & 729,6 & 21,4 & 56,96 \\
MT160_32 & 0,03 & 0,02 & 57383 & 0,08445 & 0,5 & 19.963 & 1,7 & 0,17145 & 1,7 & 0,96 & 1302,9 & 9,7 & 1114,3 & 11,7 & 1020,1 & 15,7 & 78,3 \\
\hline
\end{tabular}

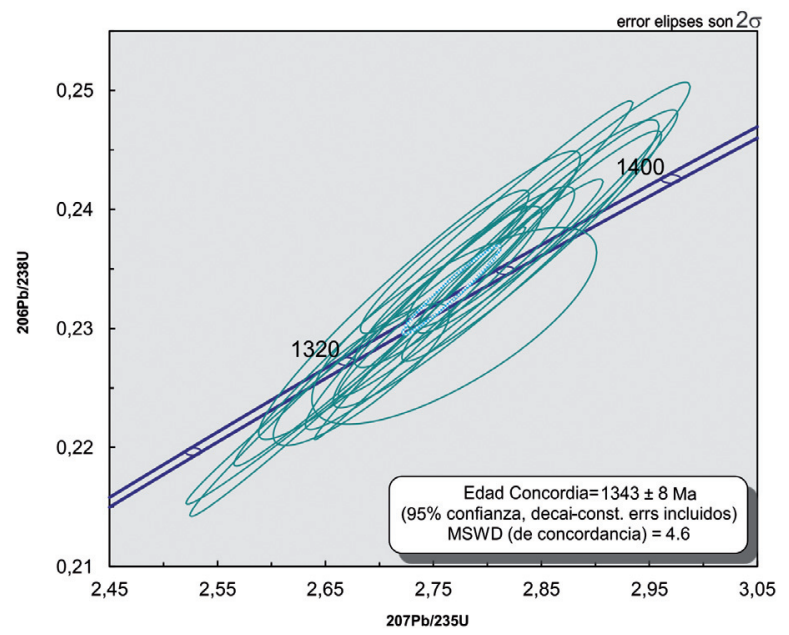

FIGURA 12. Plot de las edades concordantes $\mathrm{U} / \mathrm{Pb}$ derivadas de circones extraídos del Granito Rapakivi de Matraca.

\section{DISCUSIÓN Y CONCLUSIONES}

El basamento cristalino de rocas metamórficas y granitoides en el departamento de Guainía ha sido designado como parte del Complejo Mitú (López et al., 2007). Tres grupos de datos geocronológicos fueron obtenidos en la década de los 80 por Priem et al. (1982) mediante el método de $\mathrm{Rb} / \mathrm{Sr}$ en roca total. Dichos autores determinaron que los datos de 1.780 Ma corresponden al enfriamiento del complejo, mientras que edades entre 1.575-1.450 Ma sugieren la cristalización de cuerpos graníticos que consideraron asociada con el Evento Magmático Parguaza descrito en territorio venezolano por Gaudette et al. (1978). Finalmente, las edades entre 1.200-1.100 Ma obtenidas por el método $\mathrm{Rb} / \mathrm{Sr}$ y $\mathrm{K} / \mathrm{Ar}$ en biotitas y moscovitas fueron interpretadas como un reseteo 
por metamorfismo de bajo grado asociado al evento Nickeriense. Éstas han sido la base durante muchos años para interpretar la evolución geológica del NW del Cratón Amazónico y del Complejo Mitú (Tassinari and Macambira, 1999; Santos et al., 2006; Priem et al., 1982; López et al., 2007).
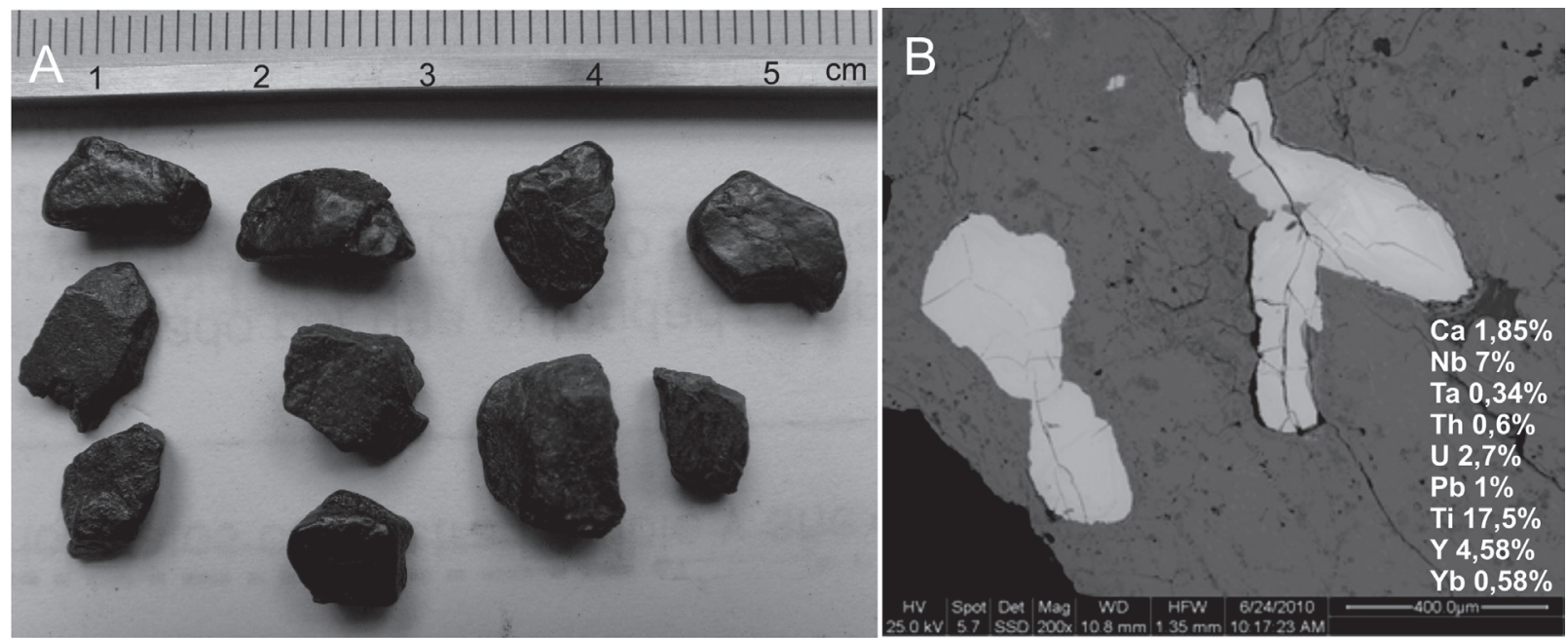

FIGURA 13. A. Cristales de ilmenita colectados en depósitos coluviales de Cerro Lluvia. B. Microfotografía de ilmenita con inclusiones de minerales enriquecidos en $\mathrm{Nb}$, REE, entre otros, (Cramer et al., 2011)

El granito rapakivi de Matraca tiene algunas características de los granitos tipo I, pero por la presencia de biotita y magnetita y sus características geoquímicas corresponde más a los granitos tipo A. Estos cuerpos graníticos son locales y difieren notablemente de los granitoides y gneises observados en el río Inírida pertenecientes a la unidad designada como Complejo Mitú por López et al. (2007). Su ocurrencia puede representar para el Complejo Mitú un rifting continental facilitando una intrusión magmática durante el Mesoproterozoico temprano (edad del granito), como producto del adelgazamiento extensional de la corteza. Tassinari (1996) describe los granitos anorogénicos como resultado de eventos extensión transarco hace 1,5 Ga como respuesta a procesos de subducción.

Los estudios de campo y petrográficos mostraron que los cuerpos graníticos aflorantes en las comunidades indígenas de Danta y Matraca, en la cuenca media del río Inírida, designado aquí como el granito rapakivi de Matraca, presentan textura rapakivi tipo piterlita y se encuentran suprayacidos discordantemente por rocas sedimentarias del Terciario y depósitos cuaternarios. Este cuerpo, junto con otros granitos presentes en el departamento, podrían asociarse con el gran Evento Parguenze entre 1.575-1.450 Ma descrito por Gaudette et al. (1978) y Priem et al. (1982). Sin embargo, las nuevas edades para el granito rapakivi de Matraca de 1.343 +/$8 \mathrm{Ma}$ obtenidas por el método LA-ICP-MS U-Pb en circón, permiten concluir que los procesos magmáticos en esta región son más complejos y prolongados y no se pueden limitar a una única "Suite Intrusiva Parguaza (MP-Sip)" intruyendo el Complejo Mitú.

Las recientes edades de 1.390-1.400 Ma para el Granito de Parguaza en sus zonas distales dentro del territorio colombiano, pueden haber sido originados por cristalización episodica (>100 Ma) de un magma distal del cuerpo intrusivo inicial que no sufrió cambios composicionales marcados y el cual posiblemente corresponde al datado en Venezuela $1.545 \mathrm{Ma}$ por Gaudette et al. (1978). Asimismo, los granitos rapakivi de la cuenca media del río Inírida con edades de 1.343 Ma al no tener correlación temporal ni espacial con este granito representarían otro episodio.

El aumento de la tendencia aluminosa en los granitos más jóvenes (e.g. GRM), puede ser el resultado de intrusiones episódicas de varios cuerpos graníticos a medida que la extensión cortical de un sistema intraplaca o de rift continental evolucionaba, semejante a los procesos reportados en el SW del cratón, en la Provincia Estañifera de Rondônia (Bettencourt et al., 1999).

Para clarificar estas relaciones es necesario continuar fuertemente la investigación en el área, ya que es probable que las edades reportadas por métodos de baja resolución (predominantemente $\mathrm{Rb}-\mathrm{Sr}$ ) sean insuficientes y existan en el Complejo Mitú muchos más granitos de tipo anorogénico, que representen 
eventos posteriores o más jóvenes y aumentarían nuestro conocimiento sobre el Cratón Amazónico y posibles mineralizaciones de $\mathrm{Ta}, \mathrm{Nb}, \mathrm{W}$, REE etc., como elementos estratégicos para el desarrollo de Colombia.

\section{AGRADECIMIENTOS}

Gracias a la comunidad indígena de Matraca y Danta por la colaboración en el acceso y reconocimiento del área de estudio; a los proyectos en conjunto entre la Universidad Nacional de Colombia y el Servicio Geológico Colombiano (antes INGEOMINAS); al Sistema General de Regalías, especialmente el contrato 031 de 2013 entre la Gobernación de Vaupés y la Universidad Nacional de Colombia por la financiación en la comisión de campo y análisis; especialmente a Luis Bernal y Carlos Mario Celada por su asesoría. A Julián López y a otro evaluador anónimo por sus contribuciones, y finalmente al grupo GEGEMA de la Universidad Nacional de Colombia-Sede Bogotá.

\section{REFERENCIAS}

Almeida, F.F.M. de, Hasui, Y., Brito-Neves, B.B., and Fuck, R.A. 1981. Brazilian structural provinces: an introduction. Earth Science Reviews, 17(1-2): 1-29.

Amaral, G. 1974. Geologia Pré-cambriana da região Amazônica. São Paulo. Universidade de São Paulo. Instituto de Geociencias. Tesis no publ. 212p.

Anderson, J.L., and Bender, E.E. 1989. Nature and origin of Proterozoic A-type granitic magmatism in the southwestern United States of America. Lithos, 23: 19-52.

Batchelor, R.A., and Bowden, P. 1985. Petrologic interpretation of granitoid rocks series using multicationic parameters. Chemical geology, 48: 43-55.

Bayona, G., Valencia, A., Mora, A., Rueda, M., Ortíz, J., y Montenegro, O. 2008. Estratigrafía y procedencia de las rocas del Mioceno en la parte distal de la cuenca antepais de los Llanos de Colombia. Geología Colombiana, 33: 23-46.

Bettencourt, J.S., Tosdal, R.M. Leite, JR. W.B., and Payolla, B.L. 1999. Mesoproterozoic rapakivi granites of the Rondonia Tin Province, southwestern border of the Amazonian Craton, Brazil-I. Reconnaissance U-Pb geochronology and regional implications. Precambrian Research, 95: 41-67.

Bonilla, A., Amaya, Z., Franco, J.A., y Cramer, T. 2010. Caracterización de depósitos aluviales en la comunidad de Matraca, departamento de Guainía, Colombia. VI Congreso Uruguayo de Geología, Minas-La Valleja, Uruguay.

Bonilla, A., Frantz, J.C., Charao, J., Cramer, T., Franco, J.A., Mulocher, E., y Amaya, Z. 2013. Petrografía, geoquímica y geocronología del Granito de Parguaza en Colombia. Boletín de Geología. 35 (2): 83-104.

Bühn, B., Pimentel, M.M., Matteini, M., and Dantas, E.L. 2009. High spatial resolution analysis of $\mathrm{Pb}$ and $\mathrm{U}$ isotopes for geochronology by laser ablation multicollector inductively coupled plasma mass spectrometry (LA-MC-IC-MS). Anais da Academia Brasileira de Ciências, 81(1): 1-16.

Campbell, E.M. 1997. Granite landforms. Journal of the Royal Society of Western Australia, 80: 101-112.

Cordani, U.G. and Brito-Neves, B.B. 1982. The geologic evolution of South America during the Archean and Early Proterozoic. Revista Brasileira de Geociências, São Paulo, 12(11-3): 78-88.

Cordani, U.G., Tassinari, C.C.G., Teixeira, W., Basei, M.A.S. e Kawashita, K. 1979. Evolução tectônica da Amazônia com base nos dados geocronológicos. II Congreso Chileno de Geologia, Arica, Chile, Actas, pp. 137-148.

Costa, J.B.S., e Hasui, Y. 1997. Evolução geológica da Amazônia. Contribuições à geologia da Amazônia. Belém: SBG, Belém, pp. 15-19.

Cramer, T., Bonilla, A., Franco, J.A., Amaya, Z., and Iregui, I. 2010a. Mineralizations of tantalum and niobium in Vichada and Guainía, eastern part of Colombia. Acta Mineralogica-Petrographica, Abstract Series, 6: 223.

Cramer, T., Graupner, T., Bonilla, A., Franco, J.A., y Amaya, Z. 2010b. Erste einblicke in Taund $\mathrm{Nb}$ - mineralisierungen im kolumbianischen Amazonasgebiet. Frankfurt, Vortrag DMG Sektionstreffen Petrologie/Petrophysik, GoetheUniversität Frankfurt, 26.6.2010.

Cramer, T., Bonilla, A., Franco, J.A., Amaya, Z., y Poveda, A. 2011. Caracterización de depósitos aluviales con manifestaciones de Tantalio y Niobio (Coltán) en las comunidades indígenas de Matraca y Caranacoa en el departamento del Guainía. Versión 1.0, Instituto Colombiano de Geología y Minería, Bogotá. 190p. 
Collins, W.J., Beams, S.D., White, A.J.R. and Chappell, B.W. 1982. Nature and origin of A-type granites with particular reference to south-eastern Australia, Contributions to Mineralogy and Petrology, 80: 189-200.

Eby, G.N. 1992. Chemical subdivision of the A-type granitoids: petrogenetic and tectonic implications. Geology, 20: 641-644.

Eklund, O., and Shebanov, A.D. 1999. The origin of rapakivi texture by sub-isothermal decom-pression. In: I. Haapala, O.T. R/im6 (Eds.), Rapakivi granites and related rocks. Pre cambrian Research, 95: 129-146.

Franco, R. 1982. Interpretation of radar imagery in the Amazonia region, Colombia, in Laming, D.J.C., and Gibbs, A.K., eds., Hidden wealth: mineral exploration techniques in tropical forest areas - Proceedings of a symposium on mineral exploration techniques in tropical forest areas, held in Caracas, Venezuela, Nov 19-23, 1977, Volume AGID Report no. 7: New York, Association of Geoscientists for International Development, pp. 154-155.

Frost, B.R., Barnes, C.G., Collins, W.J., Arculus, R.J., Ellis, D.J., and Frost, C.D. 2001. A geochemical classification for granitic rocks. Journal of Petrology, 42: 2033-2048.

Galvis, J., Huguett, A., y Ruge, P. 1979. Geología de la Amazonía Colombiana. Bogotá, INGEOMINAS, 86p.

Gaudette, H.E., Mendoza, V., Huerley, P.M., and Fairbairn, H.W. 1978. Geology and age of the Parguaza rapakivi Granite, Venezuela. Geological Society of America Bulletin, 89: 1335-1340.

Gómez, J., Nivia,A., Montes, N., Jiménez, D., Sepúlveda, J., Gaona, T., Osorio, J., Diederix, H., Mora, M., y Velásquez, M., Compiladores. 2007. Atlas Geológico de Colombia. Escala 1:500.000. INGEOMINAS, 26 planchas. Bogotá.

Haapala, I., and Rämö, O. T. 1999. Rapakivi granites and related rocks: an introduction. In: Haapala, I., and Rämö O.T. (Eds.), Rapakivi granites and related rocks. Precambrian Research Spetial Issues, 95 (1): 1-7.

Hasui, Y., and Almeida F.F.M. de. 1985. The Central Brazil shield reviewed. Episodes, 8: 63-80.

Horton, B.K., Parra, M., Saylor, J.E., Nie, J., Mora, A., Torres, V., Stockli, D.F., and Strecker, M.R. 2010. Resolving uplift of the northern Andes using detrital zircon age signatures. GSA Today, 20(7): 4-9.
Huguett, A. 1982. The geology of Guainía, Colombia, based on radar imagery. In Laming, D.J.C., and Gibbs, A.K., eds., Hidden wealth: mineral exploration techniques in tropical Forest areas - Proceedings of a symposium on mineral exploration techniques in tropical forest areas held in Caracas, Venezuela, Nov 19-23, 1977, Volume AGID Report no. 7: New York, Association of Geoscientists for International Development, p.p. 156.

INGEOMINAS. 2002. Plancha 5-16, Atlas Geológico Digital de Colombia, escala 1:500.000, Versión 1.1, Instituto Colombiano de Geología y Minería. Bogotá.

INGEOMINAS. 2010. Geología de la Plancha 297 Puerto Inírida, Instituto Colombiano de Geología y Minería. Bogotá.

King, L.C. 1949. A Theory of Bornhardts. Geographical Journal, 112: 83-87.

Lamus, F., Bayona, G., Cardona, A. y Mora, A. 2013. Procedencia de las unidades cenozoicas del Sinclinal de Guaduas: implicación en la evolución tectónica del sur del Valle Medio del Magdalena y orógenos adyacentes. Boletín de Geología, 35(1): 17-42.

Loiselle, M.C., and Wones, D.S. 1979. Characteristics and origin of anorogenic granites. Geological Society of America, abstracts with programs 11, 468.

López, J., y Cramer, T. 2012. Ambiente geológico del Complejo Mitú y perspectivas de ocurrencias minerales de niobio y tantalio en el territorio colombiano. Geología Colombiana, 37: 75-95.

López, J., Mora, M., Jiménez, D., Khurama, S., Marín, E., Obando, G., Páez, T., Carrillo, E., Bernal, L., y Celada, C. 2010. Cartografía geológica y muestreo geoquímico de las planchas 297 - Puerto Inírida, 297 Bis - Merey y 277 Bis - Amanaven, departamento del Guainía. Memoria, Bogotá. 156p.

López, J., Khurama, S., Bernal, L., y Cuéllar, M. 2007. El Complejo Mitú: una nueva perspectiva. XI Congreso Colombiano de Geología, Bucaramanga. p.p.16.

Ludwig, K.R. 2003. Isoplot 3.00 - A geochronological toolkit for Microsoft Excel. Berkeley Geochronology Center. Special Publication No 4, 52p.

Maniar, P.D., and Piccoli, P.M. 1989. Tectonic discrimination of granitoids. Geological Society of America Bulletin, 101: 635-643. 
Middlemost, E.A.K. 1985. Magmas and magmatic rocks: an introduction to igneous petrology. Longman, London. 266p.

Peccerillo, A., and Taylor S.R. 1976. Geochemistry of Eocene calc-alkaline volcanic rocks from Kastmonu area, Northern Turkey. Contributions to Mineralogy and Petrology, 58: 63-81.

Pearce, J.A., Harris, N.B.W., and Tindle, A.G. 1984. Trace element discrimination diagrams for the tectonic interpretation of granitic rocks. Journal of Petrology, 25: 956-983.

Priem, H., Andriessen, P., Boelrijk, N., Boorder, H. de, Hebeda, E., Huguett, A., Verdumen, E., and Verschure, R. 1982. Geochronology of the Precambrian in the Amazonas region of southeastern Colombia (Western Guainía Shield). Geol. Minjnbouw, 61: 229-242.

Rämö, O. T., and Haapala, I. 1995. One hundred years of rapakivi granites. Mineralogy and Petrology, 52: 129-185.

Rämö, O.T., and Haapala, I. 2005. Rapakivi granites. In: Lehtinen, M., Nurmi, RA., Rämö, O.T. (Eds.), Precambrian Geology of Finland - Key to the Evolution of the Fennoscandian Shield. Elsevier B.V., Amsterdam, pp. 533-562.

Santos, J.O.S., e Loguercio, S.O.C. 1984. A parte meridional do Craton Amazonico (Escudo Brasil Central) e as bacias do Alto Tapajós e Parecis-Alto Xingu. In: Schobbenhaus Filho, C.; Campos, D.A.; Derze, G.R.; Asmus, H.E. (Coord.) Geologia do Brasil: Texto Explicativo do Mapa Geologico do Brasil e da Área Adjascente incluindo Depositos Minerais, Brasilia, DNPM/MME, pp. 93-127.

Santos, J.O.S., Hartmann, L.A., Faria, M.S.G.D., Riker, S.R.L., Souza, M.M.D., Almeida, M.E., e Mcnaughton, N.J. 2006. A Compartimentação do Cráton Amazonas em províncias: avanços ocorridos no período 20002006. 9 ed. S.N. Norte. Belém.

Santos, J.O.S., Hartmann, L.A., Gaudette, H.E., Groves, D.I., Mcnaughton, N.J. and Fletcher, I.R. 2000. A new understanding of the provinces of the Amazon Cráton based on integration of field mapping and U-Pb and SmNd geochronology. Gondwana Research, 3(4): 453-488.

Sato, K., e Tassinari, C.C.G. 1997. Principais eventos de acreção continental no Cráton Amazônico baseados em idade modelo $\mathrm{Sm}-\mathrm{Nd}$, calculada em evoluções de estágio único e estágio duplo. In: Costa, M.L. and
Angélica, R.S., eds, Contribuições à Geologia da Amazônia, Belém, SBG, pp. 91-142.

Shand, S.J. 1943. Eruptive rocks: their genesis, composition, and classification, with a chapter on meteorites. Second edition. J. Wiley \& sons, inc, London, 444p.

Streckeisen, A. 1967. Classification and nomenclature of igneous rocks. Final report of an inquiry. Neues Jahrbuch für Mineralogie, Abhandlungen, 107: 144-204.

Tassinari, C.C.G., and Macambira, M.J.B. 1999. Geological provinces of the Amazonian Craton. Episodes, 22: 173-182.

Tassinari, C.C.G. 1996. O Mapa Geocronológico do Craton Amazônico no Brasil: Revisão dos Dados Isotópicos. São Paulo, (Tese de Livre Docência) Instituto de Geociências, Universidade de São Paulo. 139p.

Tassinari, C.G., Cordani, U.G., Nutman, A.P., Van Schmus, W.R., Bettencourt, J.S., and Taylor, P.N. 1996. Geochronological systematics on basement rocks from the Rio Negro-Juruena province (Amazon Craton) and tectonic implications. International Geology Review, 40: 71-114.

Teixeira, W., Tassinari, C.G., Cordani, U.G. and Kawashita, K. 1989. A review of the geochronology of the Amazonian Craton: Tectonic implications. Precambrian Research, 42: 213-227.

Tkachev, A.V. 2011. Evolution of metallogeny of granitic pegmatites associated with orogens throughout geological Time. In: Sial, A.N., Bettencourt, J.S., De Campos, C.P., and Ferreira, V.P. (eds) Granite- Related Ore Deposits. Geological Society, London, Special Publications, 350 (1): 7-23.

Twidale, C.R. 1982. Granite Landforms. Elsevier, Amsterdam. 372p.

Vorma, A. 1976. On the petrochemistry of rapakivi granites with special reference to the Laitila Massif, southwestern Finland. Geological Survey of Finland, Bulletin 285, 98p.

Whalen, J.B., Currie, K.L., and Chappell, B.W. 1987. A-type granites: geochemical characteristic, discrimination and petrogenesis. Contributions to Mineralogy and Petrology, 95: 407-418.

Trabajo recibido: agosto 15 de 2014

Trabajo aceptado: junio 24 de 2015 